\title{
Guest Editor Introduction to the Book Symposium on Shannon Vallor, Technology and the Virtues: A Philosophical Guide to a Future Worth Wanting. Oxford: Oxford University Press, 2016
}

\author{
Diane P. Michelfelder ${ }^{1}$
}

Published online: 30 May 2018

(C) Springer Science+Business Media B.V., part of Springer Nature 2018

In The Scent of Time (Polity, 2017), the philosopher Byung-Chul Han observes that today things "linked to time become obsolete much faster than they used to" (p.5). A similar point could be made about ethical paradigms as well, as the time period in between announced needs for new ethical approaches to the technological intensification of the world in which we dwell continues to shrink. Hans Jonas argued in 1984 for a new ethic of responsibility for a new technological age, and others have claimed that the cyberspace technologies spawned in the 1990s has changed our moral condition in such a way that past ethical theories cannot sufficiently deal with. In her Technology and the Virtues: A Philosophical Guide to a Future Worth Wanting (Oxford, 2016), Shannon Vallor argues that the current and emerging technological landscape not only invites but requires a new ethical paradigm. "The ethical dilemmas we face as $21^{\text {st }}$ century humans are not business as usual, but require a novel approach" (p.9).

Still, novel approaches do not arise ex nihilo; what is familiar in philosophy can also make new and significant waves. Witness the recent resurgence of interest in virtuebased ethics, which has taken root not only in ethical theory but also in environmental ethics, engineering ethics, and other applied ethical fields. Acknowledging this resurgence, Vallor says bluntly that "it is time to add technosocial ethics to this growing list" (p.33). Technology and the Virtues represents a pioneering work in a virtue-based ethics of technology. A notable aspect of Vallor's vision in this volume is the breadth of its aperture. As one would expect from any applied ethics, part of Vallor's focus is on individual types of artifacts. She considers how an ethics of technology grounded in the virtues inspired from classical virtue ethics traditions could help us live with particular new technologies - including surveillance technologies, social media, and carebotswith greater moral attentiveness and wisdom. But she also seeks to use the virtues, of

Diane P. Michelfelder

michelfelder@macalester.edu

1 Department of Philosophy, Macalester College, 1600 Grand Avenue, Saint Paul, MN 55105, USA 
which she identifies twelve "technomoral" ones as being of particular importance for the contemporary world, as a foundation for a "global technomoral virtue ethic" that could point the way for individuals to live more flourishing lives.

The papers assembled here with this volume as a focus were first prepared for an "Author Meets Critics" session sponsored by the Society for Philosophy and Technology which took place at the 2017 Central Division meeting of the American Philosophical Association. All too often, such sessions contribute to the tally of ephemera in the academic sphere. Their content is accessible only for those able to attend a meeting in person. The publication of this exchange in this journal provides a refreshing counterweight by presenting opportunities for a wider exposure to and understanding of the debates involved in the complex issues which the papers in this session reflect. The hope here is also that it might engage readers in reflection on further questions, such as the question of the role of engineering design and design research in fostering and sustaining the development of the technomoral virtues discussed here.

In the first of these papers, Emily McRae looks at Vallor's book from the perspectives of Buddhist ethics. Her primary concern is a methodological one. Suspecting that Vallor ends up reading Buddhist thought through an Aristotelian lens rather than engaging with it directly, she worries that this lens has caused key ideas central to Buddhism, such as the concept of the no-Self and liberation from the human condition, to disappear from view. But the overall tenor of McRae's thoughts, like those of the other two commentators represented here, is a constructive one. In particular, McRae proposes that the Buddhist concept of bodhicitta could provide a theoretical grounding for many of the virtues that Vallor emphasizes as being important to cultivate in order to live well in a world ever increasingly shaped by technology, including empathy, moral attentiveness, and the importance of having a flexible or "soft" mind.

In the middle paper of this trio of commentaries, Howard Curzer takes issue with Vallor's central claim that the virtues she singles out as "technomoral" are made more necessary by an environment where more and more ordinary human interactions are facilitated by technological means. At the same time, though, he acknowledges that flexibility does stand out as a technomoral virtue. He also extends Vallor's view by saying that our present technological condition demands not simply more of the same old virtues, but new forms of old ones, including justice and courage. Without going into detail, Curzer suggestively posits that as our technological condition continues to take shape and intensify, "moral imagination will become even more necessary than it is now." His commentary concludes on a questioning note. How can contemporary virtue ethics account for the difficulty of developing moral habits in a time of constant change? Are we not already in some sense trans-human beings?

Rounding out the critical commentaries, Don Howard takes Vallor's designation of "flexibility" as a technomoral virtue a step further by discussing how the concept of this virtue could be more fully developed. Raising a question that does not come up in the other two papers, Howard wonders if there is a missing element to Vallor's volume: namely, a consideration of the civic virtues, and in particular the civic virtues associated with the communities of those who deal directly with technology as makers and practitioners. Drawing upon a variety of examples of such professional communities, such as the Human-Robot Interaction community associated with IEEE, Howard demonstrates the need for opening up Vallor's technomoral virtue ethics approach to 
include such virtues and takes a step down this path himself by proposing "Socratism" - the virtue of moral scrutiny and whistleblowing - as a case in point.

Turning to Vallor's response to the three commentaries, we find her approaching them in expanding order of critical scope. While unhesitatingly acknowledging the reasonableness of some of her critics' comments, such as McRae's suggestion concerning the role that the Buddhist concept of bodhicitta could play in her project; she also clarifies how Buddhist ethics is not simply a theoretical add-on for her work but plays a key role in helping to inspire the moral imagination. She does not hold back from expressing her concerns about other comments, such as Curzer's suggestion that the virtue of care becomes outmoded when technologies can "proxy" for caring human beings. And, she expresses wholehearted agreement with Howard's suggestion that more needs to be done with respect to the civic virtues, accepting "Socratism" and adding mediation of differences to the list. In this way, she moves from the commentaries toward the question of "next steps" in her own technomoral virtue research program, and so, we can hope, to the possibility of another "author meets critics" session in the future as engaging as this one. 